\title{
Gastric regurgitation in patients undergoing gynecological laparoscopy with a laryngeal mask airway: a prospective observational study ${ }^{\text {ts }}$
}

\author{
Jeconias Lemos MD (Attending Anesthesiologist) ${ }^{a}$,
}

Gildasio S. De Oliveira Jr. MD, MSCI (Vice Chair for Research and Faculty Affairs) ${ }^{\text {b,* }}$, Hugo Eckner Dantas de Pereira Cardoso MD (Attending Aanesthesiologist) ${ }^{a}$, Lavínia Dantas Cardoso Neiva Lemos (Medical Student) ${ }^{\text {C }}$, Lígia Raquel de Carvalho MD (Professor) ${ }^{\text {, }}$, Norma Suely Pinheiro Módolo MD (Professor) ${ }^{e}$

${ }^{a}$ Department of Anesthesiology, Royal Spanish Charitable Society/Hospital (Real Sociedade Espanhola de Beneficência/Hospital), Madrid, Spain

${ }^{\mathrm{b}}$ Department of Anesthesiology, Feiberg School of Medicine, Northwestern University, Chicago, IL

${ }^{\mathrm{c}}$ School of Biosciences, UNESP, Botucatu, Spain

${ }^{\mathrm{d}}$ Bahia School of Medicine and Public Health, EBMSP

${ }^{\mathrm{e}}$ Department of Anaesthesiology, Botucatu Medical School of Medicine, UNESP, Spain

Received 2 April 2015; revised 6 July 2016; accepted 25 July 2016

Keywords:

LMA;

Laparoscopy;

Regurgitation

\begin{abstract}
Objective: The use of pneumoperitonium and the placement of patients in Trendelenburg position are commonly cited reasons for the potential development of intraoperative regurgitation of gastric contents and the need for an endotracheal tube in laparoscopic surgery. The main objective of the current investigation was to evaluate the presence of regurgitation of gastric contents in the oropharynx of patients having laparoscopic gynecological surgery with a laryngeal mask airway (LMA).

Design: Prospective, observational clinical investigation.

Interventions: Not applicable.

Measurements: Healthy subjects having a laparoscopic gynecological surgery under general anesthesia with a ProSeal LMA were included in the study. An insufflation pressure of $15 \mathrm{~mm} \mathrm{Hg}$ was established as the maximum intra-abdominal pressure for the pneumoperitonium, and patients were placed in Trendelenburg position at a $15^{\circ}$ angle. The $\mathrm{pH}$ of secretions extracted from subjects' hypopharynx was measured at multiple time points during the surgical procedure. A pH of oropharynx secretions $\leq 4.1$ indicated the regurgitation of gastric contents.

Main results: Eighty subjects were recruited and completed the study. The median (range) of $\mathrm{pH}$ measurements at any time (T3-T9) was 6.5 (5.5-7.0). The median (range) for the lowest $\mathrm{pH}$ for each subject was 6.0
\end{abstract}

\footnotetext{
is Funding: Department of Anesthesiology at the Royal Spanish Charitable Society/Hospital (Real Sociedade Espanhola de Beneficência/Hospital).

* Corresponding author at: Department of Anesthesiology, Feinberg School of Medicine, Northwestern University, 251 East Huron St F5-704, Chicago, IL 60611. Tel.: +1 3124723573 .

E-mail address: g-jr@northwestern.edu (G.S. De Oliveira).
} 
(5.5-7.0). The lowest detected $\mathrm{pH}$ in the hypopharynx was not correlated (Spearman $\rho$ ) with total surgical time $(P=.9)$, total pneumopertitonium time $(P=.17)$, or total Trendelenburg position time $(P=.47)$.

Conclusions: Our current results suggest that the use of an LMA in healthy patients undergoing laparoscopic gynecological surgery may be safe. Future studies to confirm or refute our findings are warranted.

(C) 2016 Elsevier Inc. All rights reserved.

\section{Introduction}

Patients having surgery under general anesthesia have better postsurgical recovery when a laryngeal mask airway (LMA) is used compared with an endotracheal tube [1]. Nonetheless, the risk of aspiration pneumonitis frequently leads clinical practitioners to choose an endotracheal tube instead of an LMA for patients undergoing laparoscopic procedures [2-4]. The use of pneumoperitonium and the placement of patients in Trendelenburg position in laparoscopic surgery are commonly cited reasons for the potential development of intraoperative regurgitation of gastric contents and the need for an endotracheal tube [5].

Several studies have evaluated the use of LMA for laparoscopic surgery. Nevertheless, prior studies have focused on the examination of the adequacy of ventilation using the LMA rather than safety aspects related to aspiration of gastric contents. Safety analyses have been limited to report the absence of clinical aspiration and very few studies have systematically evaluated the presence of gastric regurgitation. The need for more studies evaluating the presence of gastric regurgitation in patients undergoing laparoscopic procedures with an LMA has also been suggested by a systematic review of the literature [6].

The main objective of the current investigation was to evaluate the presence of regurgitation of gastric contents in the oropharynx of patients having laparoscopic gynecological surgery with an LMA. We specifically sought to determine the $\mathrm{pH}$ of oropharynx secretions at multiple times during the surgical procedure.

\section{Methods}

This study was a prospective, observational clinical investigation. Study approval was obtained from the Royal Spanish Charitable Society/Hospital (Real Sociedade Espanhola de Beneficência/Hospital), and written informed consent was obtained from all the study participants. The study is reported following the STROBE guidelines [7]. The study was performed between August 2012 and October 2013. Eligible subjects were consecutive healthy women undergoing gynecological laparoscopy. Patients with a history of full stomach, gastroesophageal reflux disease, hiatal hernia, body mass index > $30 \mathrm{~kg} / \mathrm{m}^{2}$, diabetes mellitus, or any other conditions that might delay the passing of the gastric contents were excluded.
Reasons to drop out after inclusion in the study were the need to use an endotracheal tube or conversion to an open incision.

After fasting for at least 6 hours, subjects were taken to the operating room and standard American Society of Anesthesiologists monitors were applied. Subjects did not receive any premedication. Anesthesia was induced with fentanyl (2-4 $\left.\mu \mathrm{g} \mathrm{kg}^{-1}\right)$, propofol (1.5-2.5 $\left.\mathrm{mg} \mathrm{kg}^{-1}\right)$, and rocuronium $(0.6 \mathrm{mg} / \mathrm{kg}$ ). An LMA (ProSeal; Teleflex, San Diego, CA) size 3 or 4 following the manufacturer's recommendation according to subjects' weight was inserted by an experienced anesthesiologist, and the cuff inflation pressure was kept $\leq 60 \mathrm{~cm}$ $\mathrm{H}_{2} \mathrm{O}$. A maximum total of 3 attempts were made to place the device, and in the case of failure, orotracheal intubation was used. Anesthesia maintenance was achieved using propofol (4-12 $\left.\mathrm{mg} \mathrm{kg}^{-1} \mathrm{~h}^{-1}\right)$, remifentanil (0.1-2.0 $\left.\mu \mathrm{g} \mathrm{kg}^{-1} \mathrm{~min}^{-1}\right)$, and rocuronium $\left(0.15 \mathrm{mg} \mathrm{kg}^{-1}\right)$. Patients were ventilated with intermittent positive pressure ventilation with a tidal volume of $8 \mathrm{~mL} \mathrm{~kg}^{-1}$ and 10-12 breaths per minute were used for this study. An insufflation pressure of $15 \mathrm{~mm} \mathrm{Hg}$ was established as the maximum intra-abdominal pressure for the pneumoperitonium and patients were placed in Trendelenburg position at a $15^{\circ}$ angle.

Secretions in the hypopharynx were collected via a suction probe (one for each aspirate) inserted into the esophageal drainage tube of the LMA-ProSeal at $1 \mathrm{~cm}$ from its distal end at various defined times, as follows: T1 (baseline), after the placement of the LMA; T2, after insufflation of the abdominal cavity (pneumoperitoneum); T3, before the head-down positioning; T4, after the head-down positioning; T5, after the end of insufflation; T6, after returning to a horizontal position; T7, at the end of surgery; and T8, after removing the LMA (measured on the outside of the LMA shell near the end of the drainage tube on both sides).

To measure the $\mathrm{pH}$ of the secretions in the hypopharynx, we used pH test strips, pH 0-9 (Merck, Darmstadt, Germany), due to their reliability, high accuracy, and for already having been validated in other studies [8-10]. If the secretions were pigmented, such as in the presence of blood, which would make the $\mathrm{pH}$ test strip measurements less reliable, the collected material was measured using a bench top $\mathrm{pH}$ meter in the central laboratory for a more reliable measurement. Based on prior studies, a $\mathrm{pH}$ of $\leq 4.1$ was considered to indicate the regurgitation of gastric contents into the secretions in the hypopharynx [11].

A sample of 80 patients evaluated at 7 points of the surgical procedure (T2 through T8) would generate 560 data points. This would allow us to establish a maximum incidence of 
regurgitation $<0.8 \%$ using the Clopper-Pearson exact method for binomial interval estimations. The Shapiro-Wilk test was used to test the hypothesis of normal distribution. Normally distributed interval data are reported as mean (SD). Nonnormally distributed interval and ordinal data are reported as median (interquartile range) and it was evaluated using MannWhitney $U$ test [12]. The $95 \%$ binomial confidence interval (CI) for the incidence of regurgitation was calculated using the Jeffreys' method. The coverage properties of that method are similar to others, but it has the advantage of being equaltailed (eg, for a $95 \% \mathrm{CI}$, the probabilities of the interval lying above or below the true value are both close to $2.5 \%$ ) [13]. Nonparametric correlations were performed with the Spearman $\rho$ correlation coefficient. An analysis of changes in the $\mathrm{pH}$ across time was performed by using Friedman test. Twotailed $P$ values $<.05$ were used to reject null hypothesess. Statistical analyses were performed using STATA v13 (StataCorp, College Station, TX).

\section{Results}

Of 97 patients initially screened, 80 subjects were recruited and all completed the study. Nine patients refused to participate and 8 did not meet inclusion and/or exclusion criteria. Subjects' demographics and surgical characteristics are presented in Table 1. The median (range) of $\mathrm{pH}$ measurements at any time (T3-T9) was 6.5 (5.5-7.0). The median (range) for the lowest $\mathrm{pH}$ for each subject was 6.0 (5.5-7.0). The oropharynx $\mathrm{pH}$ values did not significantly change across different measurement times as presented in Fig. 1.

An exploratory analysis by grouping and comparing lower aspiration risk times (T1, T2, T7, and T8) to higher aspiration risk times (T3, T4, T5, and T6) did not demonstrate a significant difference in the $\mathrm{pH}$ values between the lower aspiration risk times, median (interquartile range) of 6.5 (6-7) and higher aspiration risk times of $6.0(6-7 ; P=.07)$. The lowest detected $\mathrm{pH}$ in the hypopharynx for each subject was not correlated (Spearman $\rho)$ with total surgical time $(P=.9)$, total pneumopertitonium time $(P=.17)$, or total Trendelenburg position time $(P=.47)$.

Table 1 Subjects' demographics and surgical characteristics $(\mathrm{n}=80)$

Age (y)

Body mass index $\left(\mathrm{kg} / \mathrm{m}^{2}\right)$

Fasting time (min)

Surgical time (min)

Pneumoperitonium time ( $\mathrm{min})$

Trendelenburg time ( $\mathrm{min})$

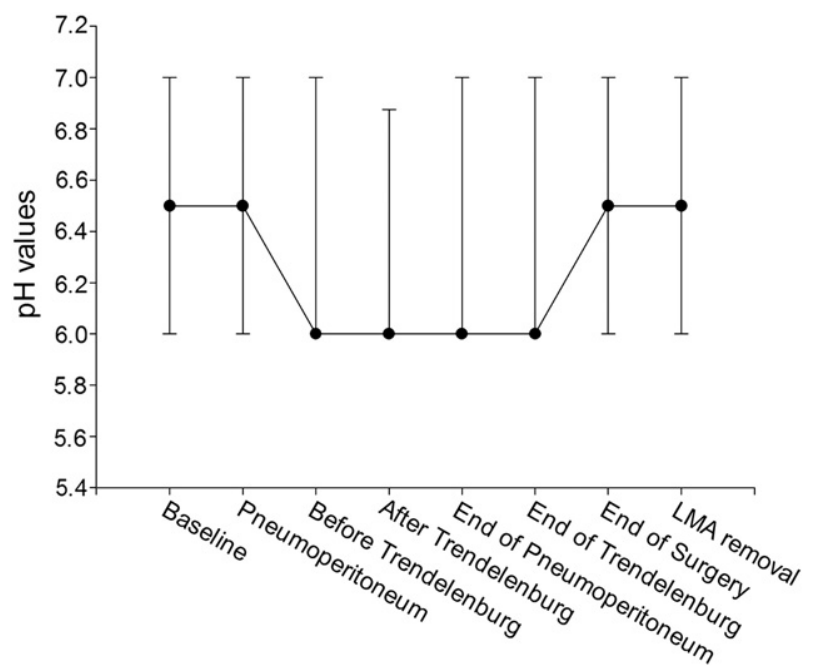

Fig. 1 Box plots demonstrating hypopharynx $\mathrm{pH}$ values across study times. Black dots represent median values. The limits of the boxplots denote $95 \%$ confidence limits. Data were analyzed using repeated measure for nonparametric data (Friedman test). There was no association between $\mathrm{pH}$ values and the different times of measurement, $P=.66$.

The estimated incidence $(95 \% \mathrm{CI})$ of regurgitation at any surgical time was $0 \%(0-0.8 \%)$. The estimated incidence $(95 \% \mathrm{CI})$ of regurgitation per study subject was $0 \%(0.1-5 \%)$.

\section{Discussion}

The most important finding of the current investigation was the lack of gastric regurgitation in patients having a gynecological laparoscopy with an LMA. We did not detect any hypopharynx $\mathrm{pH}$ values consistent with gastric regurgitation across different times of the surgical procedure. Our current results support the safety of using the LMA for airway management in patients undergoing laparoscopic gynecological procedures.

Our findings are clinically important because the use of the LMA for laparoscopic procedures remains controversial [6]. Although several studies have demonstrated adequate ventilation of patients undergoing laparoscopic surgery with an LMA, very few have systematically examined the presence of gastric regurgitation. The safety of using an LMA in laparoscopic surgery has relied mainly in the lack of cases in the literature reporting adverse events such as aspiration [14,15].

It was interesting to note in our study a change in the hypopharynx $\mathrm{pH}$ across different times of the surgical procedure. We noticed a decrease of 0.5 in the hypopharynx $\mathrm{pH}$ that happened concomitantly with the pneumoperitonium insufflation and a return to baseline values at the end of surgery. It is possible that the development of respiratory acidosis or the diffusion and mixture of carbon dioxide with pharyngeal secretions could have contributed to the detected changes. Nevertheless,

Data are described as median (interquartile range). 
all the $\mathrm{pH}$ measurements were still not consistent with regurgitation of gastric contents $(\mathrm{pH}>4.0)$.

The results of the current study support prior studies that systematically examined the presence but did not detect regurgitation in patients having laparoscopic surgery with an LMA $[16,17]$. In contrast, prior studies have used a regular LMA, instead of the Proseal LMA used in the current investigation. The use of a regular LMA may limit the ability to reliably access hypopharynx secretions, and this could have led to falsenegative results in prior studies. The Proseal LMA provides a high seal pressure and a built-in drain tube designed to channel fluid away that easily permits gastric access $[18,19]$. These characteristics of the Proseal LMA are advantageous for laparoscopic procedures requiring positive pressure ventilation when compared with the regular LMA.

Both volume and $\mathrm{pH}$ of gastric contents are important factors in the development of aspiration. Although we did not precisely measure the volumes of the aspirate content in the current study, we did not observe any sample that had a volume greater than $2 \mathrm{~mL}$. This value is substantially lower than the values associated with the development of aspiration pneumonitis. Nonetheless, future studies should precisely measure not only $\mathrm{pH}$ values but also the volume of aspirate content.

Our study should only be interpreted within the context of its limitations. We only examined healthy patients; therefore, our results cannot be generalized to patients with other comorbidities (eg, obese, gastroesophageal reflux, diabetes). Although we did not detect any regurgitation of gastric contents at any time, we could only determine a maximum incidence of $5 \%$ of regurgitation per subject in our cohort. When our results are combined with a previous study [17], a maximum incidence of regurgitation of $2.5 \%$ can be established. Nonetheless, more studies are warranted to further examine the presence of gastric regurgitation in patients undergoing laparoscopic procedures with an LMA.

Despite prior evidence demonstrating better recovery in patients having surgery with an LMA, clinical practitioners often avoid the use of LMA due to the potential risk for regurgitation of gastric contents in patients undergoing laparoscopic surgery. Our current results suggest that the use of an LMA in healthy patients undergoing laparoscopic gynecological surgery may be safe. Future studies to confirm or refute our findings are warranted. Future studies comparing the risk of complications derived from endotracheal intubation with the use LMA in this patient population and also to confirm or refute our current findings are needed.

\section{References}

[1] SH Y, Beirne OR. Laryngeal mask airways have a lower risk of airway complications compared with endotracheal intubation: a systematic review. J Oral Maxillofac Surg 2010;68:2359-76.
[2] Wang T, Huang S, Geng G. Comparison of the duration of neuromuscular blockade following a single bolus dose of rocuronium during laparoscopic gynaecological surgery vs conventional open surgery. Anaesthesia 2014;69:854-9.

[3] Staehr-Rye AK, Rasmussen LS, Rosenberg J, Juul P, Lindekaer AL, Riber C, et al. Surgical space conditions during low-pressure laparoscopic cholecystectomy with deep versus moderate neuromuscular blockade: a randomized clinical study. Anesth Analg 2014;119:1084-92.

[4] Niraj G, Kelkar A, Hart E, Horst C, Malik D, Yeow C, et al. Comparison of analgesic efficacy of four-quadrant transversus abdominis plane (TAP) block and continuous posterior TAP analgesia with epidural analgesia in patients undergoing laparoscopic colorectal surgery: an open-label, randomised, non-inferiority trial. Anaesthesia 2014;69: 348-55.

[5] Hohlrieder M, Brimacombe J, Eschertzhuber S, Ulmer H, Keller CA. Study of airway management using the ProSeal LMA laryngeal mask airway compared with the tracheal tube on postoperative analgesia requirements following gynaecological laparoscopic surgery. Anaesthesia 2007; 62:913-8.

[6] Viira D, Myles PS. The use of the laryngeal mask in gynaecological laparoscopy. Anaesth Intensive Care 2004;32:560-3.

[7] Guglielminotti J, Dechartres A, Mentré F, Montravers P, Longrois D, Laouénan C. Reporting and methodology of multivariable analyses in prognostic observational studies published in 4 anesthesiology journals: a methodological descriptive review. Anesth Analg 2014;121: 1011-29.

[8] Serratine ACP, Silva MRM. Validation of a simplified method for evaluating the salivary $\mathrm{pH}$ in children. Pesqui Bras Odontopediatr Clín Integr 2009;9:217-21.

[9] Kotaka CR. Evaluation of $\mathrm{pH}$ indicator paper in salivary buffer capacity determination. Rev Bras Anál Clín 2001;33:199-203.

[10] Tolentino ES, Chinellato LEM, Tarzia O. Avaliação do pH da saliva e da saburra lingual antes e após a utilização de soluções enxaguantes orais [Evaluation of saliva and tongue coat $\mathrm{pH}$ before and after use of mouthwashes]. Rev Bras Odontol 2009;66:257-62.

[11] DeMeester TR, Wang CI, Wernly JA. Technique, indications, and clinical use of 24 hour esophageal $\mathrm{pH}$ monitoring. J Thorac Cardiovasc Surg 1980;79:656-70.

[12] Dexter F. Wilcoxon-Mann-Whitney test used for data that are not normally distributed. Anesth Analg 2013;117:537-8.

[13] Dann RS, Koch GG. Review and evaluation of methods for computing confidence intervals for the ratio of two proportions and considerations for non-inferiority clinical trials. J Biopharm Stat 2005; 15:85-107.

[14] Galvin EM, van Doorn M, Blazquez J, Ubben JF, Zijlstra FJ, Klein J, et al. A randomized prospective study comparing the cobra perilaryngeal airway and laryngeal mask airway-classic during controlled ventilation for gynecological laparoscopy. Anesth Analg 2007; 104:102-5

[15] Teoh WH, Lee KM, Suhitharan T, Yahaya Z, Teo MM, Sia AT. Comparison of the LMA Supreme vs the i-gel in paralysed patients undergoing gynaecological laparoscopic surgery with controlled ventilation. Anaesthesia 2010;65:1173-9.

[16] Ho BY, Skinner HJ, Mahajan RP. Gastro-esophageal reflux during day case gynaecological laparoscopy under positive pressure ventilation: laryngeal mask vs. tracheal intubation. Anaesthesia 1999;53:921-4.

[17] Bapat PP, Verghese C. Laryngeal mask airway and the incidence of regurgitation during gynecological laparoscopies. Anesth Analg 1997;85: 139-43.

[18] Philip A, Kaushik V, Mushambi M. Intracuff pressures in ProSeal and Supreme airways. Anaesthesia 2014;69:183.

[19] Ghai B, Jain K, Bansal D, Wig J. End-tidal concentrations of sevoflurane and desflurane for ProSeal laryngeal mask airway removal in anaesthetised adults: a randomised double-blind study. Eur J Anaesthesiol 2014;31:274-9. 